\title{
Successful Use of Direct Splenic Vein Anastomosis to the Interposition Internal Jugular Vein Graft after Extended Pancreatoduodenectomy to Avoid Sinistral Portal Hypertension
}

\author{
Vijay W. Dhakre ${ }^{a}$ Shrikant S. Suryawanshi ${ }^{b}$ Vijay P. Shewale ${ }^{b}$ Chetan Rathod $^{a}$ \\ Sneha Tukaram Galande ${ }^{a}$ Kaiumarz S. Sethna ${ }^{a}$ \\ aDepartment of Surgery, Lokmanya Tilak Municipal General Hospital and Lokmanya Tilak Municipal Medical \\ College, Mumbai, India; 'bepartment of Cardiovascular and Thoracic Surgery, Lokmanya Tilak Municipal General \\ Hospital and Lokmanya Tilak Municipal Medical College, Mumbai, India
}

\section{Keywords}

Borderline resectable pancreatic head malignancy $\cdot$ Sinistral portal hypertension · Pancreatoduodenectomy · Portalsuperior mesenteric venous junction resection $\cdot$ Internal jugular vein interposition graft

\begin{abstract}
Splenic vein (SV) ligation may be needed during portomesenteric junction resection, in pancreatoduodenectomy. Sinistral portal hypertension is a concern if the SV is not drained. Various techniques are described to reconstruct SV to avoid the variceal formation and sinistral portal hypertension which may lead to Gl bleed. We describe a case of a 19-year-old female who underwent pancreatoduodenectomy for solid pseudopapillary neoplasm with portal-superior mesenteric vein junction resection and splenic venous was anastomosed into the interposition graft. We here share our unique experience of using an interposition internal jugular vein graft for a long venous defect and diverging morbidity of sinistral portal hypertension.

(C) 2022 The Author(s).

Published by S. Karger AG, Basel
\end{abstract}

\section{Introduction}

Borderline resectable pancreatic cancer (BRPC) may need portomesenteric venous resection which had shown improved overall survival [1]. Interposition grafts like internal jugular vein (IJV) can be used for larger defects. Splenic vein (SV) is resected in 56-69\% of such patients for an R0 resection. Sinistral portal hypertension may develop in 37-39\% in long term, after SV ligation. We share our experience of using IJV graft and SV anastomosis that can be used to avoid the morbidity associated with GI bleeding.

\section{Case Report}

A 19-year-old female presented with vague upper abdominal pain radiating to the back for 2 months, associated with nausea. She had an ill-defined lump in the epigastric region. Rest of the systemic examination was unremarkable. Transabdominal ultrasonography revealed a $5 \mathrm{~cm} \times 5 \mathrm{~cm}$ cystic lesion in the head of the pancreas. The rest of the findings were normal. Blood workup was normal. Contrast-enhanced computed tomography showed a 5.8 $\mathrm{cm} \times 6.5 \mathrm{~cm}$ solid cystic mass in the pancreatic head region which was pushing the portomesenteric venous junction without any
Karger@karger.com www.karger.com/gat

Karger $\stackrel{\text { ' }}{=}$

BOPEN ACCESS
(C) 2022 The Author(s)

Published by S. Karger AG, Basel

This is an Open Access article licensed under the Creative Commons Attribution-NonCommercial-4.0 International License (CC BY-NC) (http://www.karger.com/Services/OpenAccessLicense), applicable to the online version of the article only. Usage and distribution for commercial purposes requires written permission.
Correspondence to:

Vijay W. Dhakre, vddrvijayd@gmail.com 


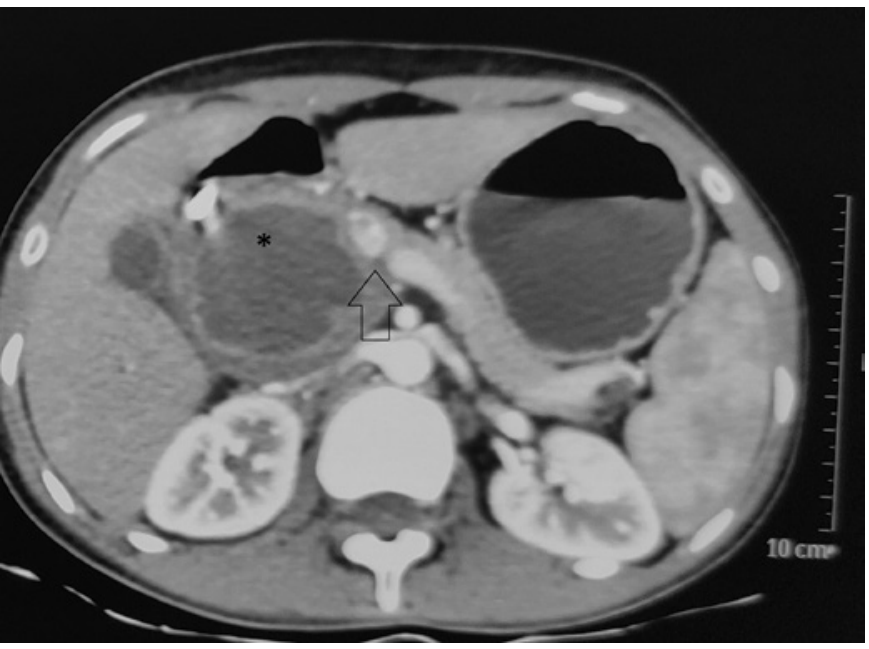

Fig. 1. Pancreatic protocol CT showing solid pseudopapillary lesion seen in the head of pancreas (* mark), (arrow) showing the close abutment of the lesion with portomesenteric and SV junction (Ishikawa type II venous invasion).

signs of involvement of invasion. No signs of locally advanced tumor (Fig. 1). The invasion of portomesenteric junction was type 2 as per Ishikawa classification. Endoscopic ultrasound-guided fineneedle aspiration was done which confirmed the diagnosis of solid pseudopapillary neoplasm.

Pancreatoduodenectomy was done with portomesenteric junction resection as the tumor closely adhered from the posterolateral wall of the portal vein (PV) and superior mesenteric vein (SMV). Hence, distal PV and SMV along with SV near its junction was resected en bloc. The final defect between PV and SMV was around $5 \mathrm{~cm}$. Primary PV-SMV anastomosis was not feasible due to a potential tension PV-SMV anastomosis.

Interposition IJV graft from the left side was harvested and tailored to fit the venous defect. IJV was anastomosed to the PV proximally and SMV distally. SV was then implanted into an IJV graft side to end (after we noted congestion in spleen) (Fig. 2). Intraoperative Doppler noted a normal portal flow. The patient had a smooth recovery, no clinically significant pancreatic fistula, and was discharged on postoperative day 8 . Histopathology showed a solid pseudopapillary neoplasm without any evidence of malignancy. Margins were clear. One-month follow-up ultrasonography confirmed no collateral formations and the spleen was normal in size; IJV graft was patent and showed normal flow. The patient is doing well 1-year post-surgery without any graft-related complications or GI bleed.

\section{Discussion}

In $\mathrm{BRPC}$, venous resection and reconstruction have shown improved long-term survival and have become the standard of care [1-3]. Ishikawa et al. [4] has classi-

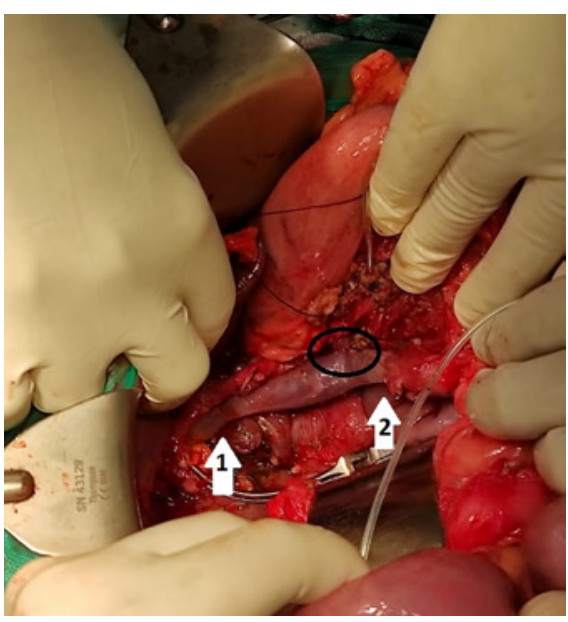

Fig. 2. Post-pancreatoduodenectomy showing proximal anastomosis (arrow 1) of PV with IJV graft and distal anastomosis (arrow 2) with SMV with IJV graft. The SV is shown (circle) implanted into the IJV graft in anatomical position.

fied the type of PV-SMV invasion as per venography into the following types: type I is a normal vein, type II is smooth shift without narrowing, type III is unilateral narrowing, type IV is bilateral narrowing, and type $\mathrm{V}$ is bilateral narrowing associated with collateral veins. Our patient had type II invasion. Alemi et al. [5] classify the involvement of portomesenteric veins in BRPC in zones (zone 1 through 5). Whereas, zone 3 (as in our case) is the commonly involved zone, necessitating a graft reconstruction [5]. International study group of pancreatic surgery (ISGPS) has recommended classification as follows: type I is direct venous closure (venorrhaphy), type II is partial venous resection and patching, type 3 is segmental venous resection and veno-venous anastomosis, and type IV is segmental resection and use of interposed grafts [6]. Our case is ISGPS type IV venous resection. SV reconstruction may be needed in certain cases otherwise can lead to left-sided or sinistral portal hypertension $(\mathrm{SPH})[1]$, which can give rise to gastric (fundic) varices $[7,8]$. The other sites that can form varices are the hepatic flexure varix, pancreatojejunostomy varices, gastrojejunostomy varices, and esophageal varices $[7,8]$. It is argued SPH post-PD does not occur as the left gastric veins, inferior mesenteric vein, colonic marginal veins, Arc of Barkow, and other inferior and superior collaterals pathways would work as non-varix-forming splenic venous outflow $[7,8]$. But the resection of these critical venous collaterals to 
Table 1. Different methods and interposition grafts used for venous reconstruction

\begin{tabular}{|c|c|c|c|}
\hline Method/graft used & Indication & Advantages & Disadvantages \\
\hline Direct venorrhaphy & ISGPS type 1, Ishikawa I/II & Simple, less time consuming & $\begin{array}{l}\text { May cause narrowing of venous caliber. May } \\
\text { lead to PVT, may at times have } \\
\text { compromised venous margins }\end{array}$ \\
\hline $\begin{array}{l}\text { Partial venous excision with/ } \\
\text { without peritoneal patch }\end{array}$ & ISGPS type 2, Ishikawa II/III & Simple, less time consuming & $\begin{array}{l}\text { May cause narrowing of venous caliber. May } \\
\text { lead to PVT, may at times have } \\
\text { compromised venous margins }\end{array}$ \\
\hline $\begin{array}{l}\text { Segmental venous resection } \\
\text { with primary venous } \\
\text { reconstruction }\end{array}$ & ISGPS type 3, Ishikawa II, III, IV & Better oncological margins & $\begin{array}{l}\text { Comparatively increased operating time \& } \\
\text { chances of PVT }\end{array}$ \\
\hline Interposed graft with IJV & ISGPS type 4, Ishikawa III, IV, V & $\begin{array}{l}\text { Better oncological margins, tension-free } \\
\text { repair, can cover larger venous defects }\end{array}$ & $\begin{array}{l}\text { Chances of PVT due to added anastomotic } \\
\text { sites, increased operating time and blood } \\
\text { loss } \\
\text { Needs a separate neck dissection which can } \\
\text { rarely cause donor site complications. } \\
\text { Comparatively less overall complication rate }\end{array}$ \\
\hline $\begin{array}{l}\text { Interposed graft with } \\
\text { external iliac vein }\end{array}$ & ISGPS type 4, Ishikawa III, IV, V & $\begin{array}{l}\text { Better oncological margins, tension free } \\
\text { repair, can cover larger venous defects, } \\
\text { graft harvesting from same incision }\end{array}$ & $\begin{array}{l}\text { Chances of PVT due to added anastomotic } \\
\text { sites, increased operating time and blood } \\
\text { loss. Increased donor site complications \& } \\
\text { DVT }\end{array}$ \\
\hline $\begin{array}{l}\text { Interposed graft with } \\
\text { saphenous vein (paneled) }\end{array}$ & ISGPS type 4, Ishikawa III, IV, V & Can cover larger defects & $\begin{array}{l}\text { Needs separate incision, larger anastomotic } \\
\text { site high chances of PVT, technically very } \\
\text { difficult, longer operating time and } \\
\text { increased blood loss }\end{array}$ \\
\hline $\begin{array}{l}\text { Interposed graft with left } \\
\text { renal vein }\end{array}$ & ISGPS type 4, Ishikawa III, IV, V & $\begin{array}{l}\text { Can cover longer defects, harvested via } \\
\text { same incision }\end{array}$ & $\begin{array}{l}\text { Donor site complications like thrombosis or } \\
\text { renal congestion }\end{array}$ \\
\hline Interposed graft with PTFE & ISGPS type 4, Ishikawa III, IV, V & $\begin{array}{l}\text { Can cover larger area of defect, added } \\
\text { incision or dissection not needed }\end{array}$ & $\begin{array}{l}\text { Higher chances of PVT, high blood loss } \\
\text { notes, high risk of infection }\end{array}$ \\
\hline
\end{tabular}

PVT, portal vein thrombosis; PTFE, polytetrafluoroethylene.

achieve $\mathrm{R} 0$ resection may put the patient at higher risk of SPH $[1,8]$. Incidence of SPH is around $29 \%$ in cases where SV is ligated and 7.7\% in whom SV is preserved and its associated complications are reported in 37$39 \%$ of patients $[1,9] ; 11 \%$ of patients with ligated SV experience life-threatening GI bleed $[8,10]$. These variceal hemorrhages can occur 21 weeks or 1-2 years post-PD, which at times needs endoscopic therapy. Endovascular therapy can be targeted to the embolized splenic artery at its origin. Splenectomy is needed in a few cases, which showed a reduction in these collateral variceal venous outflows $[8,9]$.

SV reconstruction becomes one of the most crucial steps during venous reconstruction $[8,10]$. SV reconstruction has been shown to reduce developments of varices postoperatively when compared to the SV ligation group (60\% vs. $100 \%)[9,10]$. SPH lacks definition; this may be due to the limited period of survival of $\mathrm{PD}$ patients, paucity of literature and studies, and less uniformity in techniques used for PD with vascular resection.

We believe, of all the methods the technique here described gives an advantage of avoiding dissection of SV over the pancreas, or other potential veins for SV reconstruction. IJV proves to be a much suitable interposition graft for PV-SMV-junction reconstruction. IJV has minimal tributaries which make it easy to use as a full-length interposition graft, also the diameter of IJV is similar to that of the native PV. Making it a well-matched graft and also keeping the Portal blood flow patterns physiological $[8,11-13]$. Interposition grafts like IJV give the surgeon flexibility to reconstruct larger venous defects [13]. IJV is used in a few case series with better results, since its 1 st 15 used in 1995 [11]. Hirono et al. [13] analyzed 14 patients who underwent PV-SMV-junction reconstruction. External iliac vein and IJV were used for reconstruction. Ex- 
ternal iliac vein has been associated with donor area complications and none of the patients in the IJV group had any regional complications. R0 resection and overall survival were similar in patients with graft and no graft group $(p=0.129$ and $p=0.323)$ [13].

Pantoja et al. [12] study concluded statistically similar outcomes when interposition grafts like a paneled saphenous vein graft and IJV were used. Of the 5 IJV used as interposition graft showed similar outcomes and mortality when compared to paneled saphenous vein graft. But in saphenous vein, the reconstruction was more complex and had a longer operating time than IJV grafts. Ravikumar et al. [14] study also confirmed that using interposition grafts (like IJV) does not affect R0 resection, hospital stay, or morbidity. Although they found a higher risk of PV thrombosis in this group no significant difference was seen in overall survival. But tailoring the graft dimensions, avoiding undue tension on the anastomosis, and keeping a "growth factor" while completing the PV \& SMV site anastomosis can eliminate the issues of graft thrombosis. Table 1 summarizes different methods and interposition grafts used for venous reconstruction in extended pancreaticoduodenectomy $[5,6]$.

\section{Conclusion}

Thus, our technique of anastomosing SV into the IJV graft after PV-SMV-junction resection and venous reconstruction will not only avoid varices formation (in long term) and sinistral portal hypertension but also avoid extensive perivascular dissection and interposition graft dimensions discrepancies. We believe that currently IJV graft may potentially serve as an interposition graft of choice for larger PV-SMV-junction reconstruction; keeping in mind that larger multicentric studies and trials are lacking to date.

\section{Statement of Ethics}

Written informed consent was obtained from the patient for publication of this case report and any accompanying images. Also consent was obtained to publish photos and hide identity. This case was reviewed by the Unit Head and Head of Department of surgery and CVTS, and it was determined that as case reports it does not require any further approvals.

\section{Conflict of Interest Statement}

The authors have no conflicts of interest to declare.

\section{Funding Sources}

No funding sources to declare.

\section{Author Contributions}

As per ICMJE Criteria for Authorship, Vijay W. Dhakre designed the article and also contributed in conception and literature search. Shrikant S. Suryawanshi contributed in analysis and literature search. Vijay Shewale contributed in literature search and procured case details and photographs. Chetan Rathod contributed in literature search and proof reading; Sneha Galande contributed in designing the article, literature search, and discussion analysis; and K.S.Sethna contributed in literature search and did final proof reading.

\section{Data Availability Statement}

All data generated or analyzed during this study are included in this article. Further inquiries can be directed to the corresponding author.

\section{References}

1 Shiihara M, Higuchi R, Izumo W, Yazawa T, Uemura S, Furukawa T, et al. Retrospective evaluation of risk factors of postoperative varices after pancreaticoduodenectomy with combined portal vein resection. Pancreatology. 2020 Apr;20(3):522-8.

2 Yu X, Bai X, Li Q, Gao S, Lou J, Que R, et al. Role of collateral venous circulation in prevention of sinistral portal hypertension after superior mesenteric-portal vein confluence resection during pancreaticoduodenectomy: a single-center experience. J Gastrointest Surg. 2020;24(9):2054-61.
3 Ono Y, Matsueda K, Koga R, Takahashi Y, Arita J, Takahashi M, et al. Sinistral portal hypertension after pancreaticoduodenectomy with splenic vein ligation. Br J Surg. 2015; 102(3):219-28.

4 Ishikawa O, Ohigashi H, Imaoka S, Furukawa $\mathrm{H}$, Sasaki Y, Fujita M, et al. Preoperative indications for extended pancreatectomy for locally advanced pancreas cancer involving the portal vein. Ann Surg. 1992;215(3):231-6.
5 Alemi F, Rocha FG, Helton WS, Biehl T, Alseidi A. WITHDRAWN: classification and techniques of en bloc venous reconstruction for pancreaticoduodenectomy. HРB. 2016; 18(10):827-34

6 Bockhorn M, Uzunoglu FG, Adham M, Imrie C, Milicevic M, Sandberg AA, et al. Borderline resectable pancreatic cancer: a consensus statement by the International Study Group of Pancreatic Surgery (ISGPS). Surgery. 2014; 155(6):977-88. 
7 Rosado ID, Bhalla S, Sanchez LA, Fields RC, Hawkins WG, Strasberg SM. Pattern of venous collateral development after splenic vein occlusion in an extended whipple procedure (Whipple at the Splenic Artery) and longterm results. J Gastrointest Surg. 2017;21(3): 516-26.

8 Ono Y, Tanaka M, Matsueda K, Hiratsuka M, Takahashi Y, Mise Y, et al. Techniques for splenic vein reconstruction after pancreaticoduodenectomy with portal vein resection for pancreatic cancer. HPB. 2019;21(10):128894.

9 Petrucciani N, Debs T, Rosso E, Addeo P, Antolino L, Magistri P, et al. Left-sided portal hypertension after pancreatoduodenectomy with resection of the portal/superior mesenteric vein confluence. Results of a systematic review. Surgery. 2020;168(3):434-9.

10 Tanaka M, Ito H, Ono Y, Matsueda K, Mise $\mathrm{Y}$, Ishizawa $\mathrm{T}$, et al. Impact of portal vein resection with splenic vein reconstruction after pancreatoduodenectomy on sinistral portal hypertension: who needs reconstruction? Surgery. 2019;165(2):291-7.

11 Takayama Y, Kanamaru H, Yokoyama H, Hashimoto H, Yoshino G, Toyoda H, et al. Portal vein reconstruction using an internal jugular vein as a graft: report of a case. Surg Today. 1995;25(4):378-80.

12 Pantoja JL, Chang K, Pellionisz PA, Woo K, Farley SM. Paneled saphenous vein grafts compared to internal jugular vein grafts in venous reconstruction after pancreaticoduodenectomy. Ann Vasc Surg. 2020;65:17-24.

13 Hirono S, Kawai M, Tani M, Okada K, Miyazawa $M$, Shimizu A, et al. Indication for the use of an interposed graft during portal vein and/or superior mesenteric vein reconstruction in pancreatic resection based on perioperative outcomes. Langenbecks Arch Surg. 2014;399(4):461-71.

14 Ravikumar R, Sabin C, Abu Hilal M, Al-Hilli A, Aroori S, Bond-Smith G, et al. Impact of portal vein infiltration and type of venous reconstruction in surgery for borderline resectable pancreatic cancer. Br J Surg. 2017; 104(11):1539-48. 